\title{
Distribution, Impact, and Soil Environment of Phoma sclerotioides in Northeastern U.S. Alfalfa Fields
}

\author{
M. J. Wunsch, Department of Plant Pathology, R. R. Schindelbeck and H. M. van Es, Department of Crop and Soil \\ Sciences, and G. C. Bergstrom, Department of Plant Pathology, Cornell University, Ithaca, NY 14853
}

\begin{abstract}
Wunsch, M. J., Schindelbeck, R. R., van Es, H. M., and Bergstrom, G. C. 2007. Distribution, impact, and soil environment of Phoma sclerotioides in northeastern U.S. alfalfa fields. Plant Dis. 91:1293-1304.

We report brown root rot (BRR) of alfalfa, caused by the fungal pathogen Phoma sclerotioides, for the first time in the eastern United States. Alfalfa production fields in New York, Vermont, and New Hampshire were sampled in spring 2005, and soil characteristics were related to variability in BRR incidence and severity in two New York fields sampled extensively. BRR was detected in 8 of 10 fields sampled in New York, 6 of 7 fields sampled in Vermont, and 5 of 6 fields sampled in New Hampshire. Lesions on both roots and crowns were common in all three states, and most BRR lesions extended into the cortical tissues. Diagnostic polymerase chain reaction (PCR) of $P$. sclerotioides isolates produced a single amplicon of the expected size. In vivo conidia and pycnidia morphology of northeastern isolates was consistent with published descriptions of $P$. sclerotioides, and $P$. sclerotioides was reisolated from symptomatic lesions after pathogenicity testing. In two New York fields sampled extensively, BRR severity varied with soil strength, soil texture, soil saturation, and alfalfa stand density. The spatial pattern of BRR within fields suggests the pathogen was not recently introduced. The results suggest BRR is widespread in alfalfa production fields in New York, Vermont, and New Hampshire.
\end{abstract}

Phoma sclerotioides G. Preuss ex Sacc. (syn. Plenodomus meliloti Dearn. \& G.B. Sanford) is a low-temperature fungal pathogen of overwintering legumes $(7,18,22,42)$ and cereals (26). It causes particularly severe damage to alfalfa (Medicago sativa L.) and sweet clover (Melilotus alba Desr.). The causal agent of brown root rot (BRR) of alfalfa, sweet clover, and other forage legumes, $P$. sclerotioides causes lesions on both roots and crowns, and it is associated with yield loss $(3,4)$, slow emergence from winter dormancy (20), and winterkill $(17,40,42)$. It is primarily pathogenic to alfalfa and sweet clover roots in late winter and early spring, as plants emerge from winter dormancy $(7,42)$; it is not pathogenic during summer (7). P. sclerotioides is a saprophyte of canola (Brassica sp.) and annual cereal debris (9), and it has been found in association with a wide range of other herbaceous plants, including redroot amaranth (Amaranthus retroflexus), pigweed (Axyris amaranthoides), red fescue (Festuca rubra), Kentucky bluegrass (Poa pratensis), and winter rye (Secale cereale) $(11,31,42)$.

Corresponding author: G. C. Bergstrom

E-mail: gcb3@cornell.edu

Accepted for publication 17 May 2007.

doi:10.1094/PDIS-91-10-1293

(C) 2007 The American Phytopathological Society
Within North America, P. sclerotioides has long been known to be a problem in alfalfa and sweet clover production in Alaska and in Alberta, Saskatchewan, Manitoba, and the Yukon Territory of Canada $(31,34,42)$. It was first observed in the contiguous United States in 1996, when it was isolated from symptomatic alfalfa in Wyoming (17), and it has subsequently been associated with diseased alfalfa plants in Idaho (20), Montana (35), Minnesota (26), and Wisconsin (27). However, its occurrence and distribution in the eastern United States has not been studied.

Preliminary work conducted by the authors in 2003 and 2004 suggested that $P$. sclerotioides is present in New York (50). In spring 2003, a symptomatic alfalfa root collected in northeastern New York tested positive for the pathogen (50) using polymerase chain reaction (PCR)-based sequence-characterized amplified region (SCAR) primers developed by Larsen et al. (28). In a subsequent survey of New York alfalfa production fields in 2004 (50), cultures characteristic of $P$. sclerotioides were isolated from diseased alfalfa roots and crowns in multiple fields. Pathogenicity testing was not conducted, but diagnostic PCR of axenic single-conidium cultures yielded a single amplicon of the size expected for $P$. sclerotioides. The survey, however, did not permit an evaluation of the importance of $P$. sclerotioides to alfalfa production in New York. The severity of the lesions from which $P$. sclerotioides was isolated was not recorded, and roots were collected in some regions of the state during the summer, when $P$. sclerotioides is not isolated as efficiently (34), thereby precluding accurate assessments of BRR incidence.

In eastern North America, P. sclerotioides has been previously reported only in Nova Scotia (9). It has not been reported in Ontario, Quebec, Newfoundland, or New Brunswick, and it is unclear if the observed occurrence of BRR in New York in 2003 and 2004 was the result of a recent introduction of $P$. sclerotioides. Further, many farms in New York have a wide range of soil types both across and within production fields, and it is unclear which soil environments, and thus which fields, might be at highest risk of severe BRR losses. Soil characteristics are known to impact the severity of diseases caused by many fungal soilborne pathogens, including Fusarium solani (16), Rhizoctonia solani $(13,14)$, and Sclerotinia sclerotiorum (45), but the relationship between soil environment and BRR severity has not been studied.

Analysis of spatial patterns can be useful for inferring underlying processes, such as the origin of local epidemics $(32,43)$, and for developing testable hypotheses regarding environmental conditions favorable to an organism $(32,37)$. When a pathogen has been recently introduced at a limited number of foci within a field, as occurs when soilborne fungi are introduced with soil on unwashed equipment, the initial distribution of disease will be aggregated, with disease gradients away from the foci of introduction (33). Likewise, when underlying environmental heterogeneity differentially affects a pathogen's fitness, spatial distribution of the pathogen will correspond, at least partly, to the spatial distribution of environmental conditions favorable to the organism $(32,37)$. Multiple New York fields sampled in 2004 appeared to have an uneven distribution of alfalfa BRR (M. J. Wunsch, unpublished), suggesting possible aggregation due to recent introduction of $P$. sclerotioides or to underlying environmental heterogeneity; however, small sample sizes precluded further analysis.

The objectives of this study were (i) to confirm the presence of $P$. sclerotioides in the northeastern United States by completion of Koch's postulates, (ii) to examine the occurrence, spatial distribution, and impact of BRR in New York, Vermont, and 
New Hampshire alfalfa production fields, and (iii) to relate soil heterogeneity to observed spatial patterns of alfalfa BRR within affected fields. The impact of BRR was estimated by assessing BRR incidence, evaluating the frequency and severity of BRR lesions on both roots and crowns, and examining the relationship between BRR severity and spring regrowth.

\section{MATERIALS AND METHODS}

Survey. Ten fields in New York, seven in Vermont, and six in New Hampshire were sampled in spring 2005. In general, only fields that had passed through at least two winters were selected, and fields were selected arbitrarily by cooperators. However, two fields (New York field 2, Clinton Co., and New Hampshire field 3, Coös Co.; Table 1) were selected because of heavy winterkill losses that spring, and one field (New York field 4, Lewis Co.; Table 1) had passed through only one winter. Plants were collected at multiple sites within each field; within each sampling site, plants were arbitrarily selected without regard to vigor or apparent health. All foliage and at least $15 \mathrm{~cm}$ of the root were collected. Two fields in New York, one in Wyoming County (hereafter, "field
Wyo1") and another in Clinton County (hereafter, "field Chzl"), were sampled extensively, with approximately 30 plants collected at each of 23 sites (field Wyo1) or 24 sites (field Chz1) on an equidistant $60 \times 100 \mathrm{~m}$ or $180 \times 300 \mathrm{~m}$ grid, respectively. In all other fields, approximately 20 to 40 plants were collected from two to four sampling sites, with roughly 10 plants collected from each site; in fields with heterogeneous topography and/or soil type, sampling sites were selected such that all major field environments were represented. Fields Chz1 and Wyol were large commercial alfalfa production fields seeded in 2001; stand density was low in wet spots, but otherwise the fields were productive and appeared healthy. Both fields were rain-fed; average precipitation, as measured at nearby Burlington, VT, and Rochester, NY, respectively, is 7.9 to 10.3 $\mathrm{cm} /$ month and 6.9 to $8.6 \mathrm{~cm} / \mathrm{month}$, respectively, from May through August (2). All fields, except two in Lewis County, NY, were sampled in late April or early May 2005, shortly after alfalfa broke dormancy. The fields in Lewis County were sampled 31 May. Collected plants were double-bagged, placed on ice, transported to the laboratory, and stored at $3{ }^{\circ} \mathrm{C}$ until they were processed.
Pathogen isolation. Tissue segments were excised from roots and crowns of all alfalfa plants collected, regardless of symptoms, and surface-sterilized with $0.6 \%$ hypochlorite and $70 \%$ ethanol, rinsed with sterile distilled water, plated onto $1.5 \%$ water agar, and incubated for 3 to 6 months at $10^{\circ} \mathrm{C}$ under continuous white fluorescent light with average illuminance of 2,000 lx. Two to five tissue pieces were placed in each petri dish; 100-mmdiameter dishes were used. For each plant, separate isolations were conducted for root and for crown tissue; the crown was defined as the woody parts just above the soil line and the upper 3 to $4 \mathrm{~cm}$ of the tap root found at or just below the soil line. All plants were processed within 50 days of collection.

After the incubation period, pycnidia were harvested from the root and crown segments and/or the surrounding water agar with a sterile toothpick, dipped briefly into $95 \%$ ethanol, and transferred to potato dextrose agar (PDA; Difco Laboratories, Becton, Dickson and Co., Sparks, MD) amended with $0.3 \mathrm{~g} / \mathrm{liter}$ streptomycin sulfate salt (Sigma-Aldrich, Inc., St. Louis, MO). Because $P$. sclerotioides sometimes fails to develop the diagnostic long necks on its pycnidia during the initial incubation

Table 1. Brown root rot (BRR) incidence and severity in New York, Vermont, and New Hampshire alfalfa production fields in spring 2005

\begin{tabular}{|c|c|c|c|c|c|c|c|c|c|c|c|c|c|c|c|c|}
\hline \multirow[b]{2}{*}{ Field } & \multirow[b]{2}{*}{ County } & \multirow[b]{2}{*}{ Year $^{\mathrm{a}}$} & \multirow[b]{2}{*}{$\mathbf{B R R}^{\mathbf{b}}$} & \multirow[b]{2}{*}{ Total $^{\mathbf{c}}$} & \multirow[b]{2}{*}{$\operatorname{Root}^{\mathrm{d}}$} & \multicolumn{5}{|c|}{ BRR lesion severity, root $^{\mathrm{e}}$} & \multirow[b]{2}{*}{$\mathrm{Cr}^{\mathbf{f}}$} & \multicolumn{5}{|c|}{ BRR lesion severity, crown ${ }^{\mathrm{g}}$} \\
\hline & & & & & & 1 & 2 & 3 & 4 & 5 & & 1 & 2 & 3 & 4 & 5 \\
\hline \multicolumn{17}{|c|}{ New York } \\
\hline 1 & Clinton & 2001 & 120 & 749 & 102 & 28 & 44 & 12 & 11 & 7 & 27 & 8 & 13 & 5 & 1 & 0 \\
\hline 2 & Clinton & 2002 & 1 & 15 & 1 & 0 & 1 & 0 & 0 & 0 & 0 & 0 & 0 & 0 & 0 & 0 \\
\hline 3 & Lewis & 2003 & 1 & 27 & 0 & 0 & 0 & 0 & 0 & 0 & 1 & 0 & 1 & 0 & 0 & 0 \\
\hline 4 & Lewis & 2004 & 0 & 18 & 0 & 0 & 0 & 0 & 0 & 0 & 0 & 0 & 0 & 0 & 0 & 0 \\
\hline 5 & Steuben & 2002 & 37 & 55 & 28 & 1 & 12 & 6 & 4 & 5 & 18 & 1 & 9 & 5 & 1 & 2 \\
\hline 6 & Steuben & 2003 & 5 & 37 & 2 & 0 & 1 & 0 & 1 & 0 & 3 & 0 & 3 & 0 & 0 & 0 \\
\hline 7 & St. Lawrence & 2002 & 6 & 46 & 4 & 2 & 2 & 0 & 0 & 0 & 2 & 0 & 0 & 1 & 1 & 0 \\
\hline 8 & St. Lawrence & 2003 & 0 & 41 & 0 & 0 & 0 & 0 & 0 & 0 & 0 & 0 & 0 & 0 & 0 & 0 \\
\hline 9 & St. Lawrence & 2003 & 6 & 51 & 4 & 2 & 1 & 0 & 0 & 1 & 3 & 1 & 2 & 0 & 0 & 0 \\
\hline 10 & Wyoming & 2001 & 170 & 703 & 156 & 66 & 74 & 14 & 1 & 1 & 23 & 3 & 9 & 7 & 3 & 1 \\
\hline \multicolumn{17}{|c|}{ Vermont } \\
\hline 1 & Addison & 2001 & 21 & 44 & 11 & 2 & 6 & 2 & 1 & 0 & 12 & 0 & 6 & 4 & 2 & 0 \\
\hline 2 & Addison & 2002 & 4 & 42 & 3 & 1 & 2 & 0 & 0 & 0 & 2 & 1 & 0 & 0 & 0 & 1 \\
\hline 3 & Addison & 2002 & 22 & 43 & 10 & 3 & 2 & 3 & 2 & 0 & 16 & 0 & 6 & 2 & 7 & 1 \\
\hline 4 & Franklin & 2000 & 2 & 41 & 1 & 0 & 1 & 0 & 0 & 0 & 1 & 0 & 0 & 1 & 0 & 0 \\
\hline 5 & Grand Isle & 2002 & 17 & 38 & 16 & 8 & 7 & 1 & 0 & 0 & 3 & 0 & 2 & 0 & 1 & 0 \\
\hline 6 & Orleans & 2001 & 0 & 22 & 0 & 0 & 0 & 0 & 0 & 0 & 0 & 0 & 0 & 0 & 0 & 0 \\
\hline \multicolumn{17}{|c|}{ New Hampshire } \\
\hline 1 & Coös & 2000 & 2 & 59 & 2 & 1 & 1 & 0 & 0 & 0 & 0 & 0 & 0 & 0 & 0 & 0 \\
\hline 2 & Coös & 2003 & 5 & 33 & 3 & 0 & 0 & 1 & 2 & 0 & 2 & 0 & 1 & 1 & 0 & 0 \\
\hline 3 & Coös & 2003 & 7 & 53 & 3 & 1 & 0 & 2 & 0 & 0 & 4 & 1 & 2 & 0 & 0 & 1 \\
\hline 4 & Grafton & 2000 & 15 & 40 & 1 & 1 & 0 & 0 & 0 & 0 & 15 & 0 & 9 & 3 & 2 & 1 \\
\hline 5 & Grafton & 2002 & 17 & 43 & 9 & 2 & 4 & 0 & 2 & 1 & 10 & 0 & 6 & 2 & 2 & 0 \\
\hline 6 & Grafton & 2003 & 0 & 45 & 0 & 0 & 0 & 0 & 0 & 0 & 0 & 0 & 0 & 0 & 0 & 0 \\
\hline
\end{tabular}

a Seeding year of field.

${ }^{\mathrm{b}}$ Number of sampled plants from which Phoma sclerotioides was successfully isolated.

c Total number of plants sampled.

d Number of plants from which $P$. sclerotioides was successfully isolated from root lesions.

${ }^{\mathrm{e}}$ Number of plants with BRR root lesions in severity classes 1 to 5 , where $1=$ lesions restricted to the epidermal tissues, $2=$ lesions extend into the cortical tissues but impact $\leq 33 \%$ of root diameter, $3=$ lesions affect 34 to $66 \%$ of root diameter, $4=$ lesions affect 67 to $99 \%$ of root diameter, and $5=$ lesions completely girdle root.

${ }^{f}$ Number of plants from which P. sclerotioides was successfully isolated from crown lesions. Lesions occurring on woody tissues at or above the soil line and on the first 3 to $4 \mathrm{~cm}$ of the taproot were considered crown lesions.

${ }^{g}$ Number of plants with BRR crown lesions in severity classes 1 to 5 , where $1=$ lesions restricted to the epidermal tissues, $2=$ lesions extend into the cortical tissues but impact $\leq 33 \%$ of crown diameter, $3=$ lesions affect 34 to $66 \%$ of crown diameter, $4=$ lesions affect 67 to $99 \%$ of crown diameter, and $5=$ lesions completely girdle crown. 
period on water agar, 2 to 10 pycnidia were transferred to PDA for each root and each crown sampled regardless of pycnidial morphology. When beaked pycnidia characteristic of $P$. sclerotioides were present, spore suspensions from harvested pycnidia were used to directly establish single-conidium isolates. The cultures were incubated at $10^{\circ} \mathrm{C}$ under continuous white fluorescent light, and gross morphological characteristics were assessed 2, 4, and 8 weeks after establishment. For all cultures with gross morphological characteristics typical of $P$. sclerotioides, single-conidium isolates were established on PDA.

The single-conidium isolates were assessed for gross colony morphology and pycnidial morphology. $P$. sclerotioides pycnidia are relatively large $(0.2$ to $1.0 \mathrm{~mm}$ diameter), have one to several rostra, exude a liquid exudate from the necks prior to spore discharge, and produce a white cirrus that darkens to yellow, tan, and then brown with increasing age $(5,19)$. Because morphological characteristics of $P$. sclerotioides are variable on PDA, all isolates were also transferred to oatmeal agar (5) and to $1.5 \%$ water agar amended with autoclaved barley grains. Water agar amended with autoclaved barley grains was particularly useful for assessing $P$. sclerotioides pycnidial morphology. Pycnidia of Phoma species in section Plenodomus are variable in axenic culture and are best assessed in vivo on host tissue (5). However, screening all of the isolates on alfalfa or sweet clover root tissue was not practical; over 500 unique singleconidium isolates originating from different roots and crowns were evaluated. A subset of approximately 50 singleconidium isolates was grown on $1.5 \%$ water agar amended with both autoclaved barley grains and surface-sterilized segments of greenhouse-grown healthy alfalfa roots, incubated for 8 weeks at $10^{\circ} \mathrm{C}$ under constant light, and pycnidial morphology on the two substrates was compared. The gross morphological characteristics of $P$. sclerotioides pycnidia on barley were consistent and highly similar to the pycnidial characteristics observed on alfalfa tissue, and the remaining isolates were screened on water agar amended with barley grains. The barley grain medium was prepared by soaking hulled barley in distilled water for 4 to $6 \mathrm{~h}$, decanting the water, and autoclaving the soaked barley grains in glass petri dishes for $60 \mathrm{~min}$ twice. After cooling, approximately 5 to 20 barley grains were transferred to hardened $1.5 \%$ water agar in petri dishes. Mycelial disks, taken from the growing edge of single-conidium isolates growing on PDA, were transferred to the water agar, and cultures were incubated at $10^{\circ} \mathrm{C}$ under continuous white fluorescent light for 1.5 to 2 months.

BRR incidence. For each field, root, crown, and total BRR incidence were calculated by dividing the number of plants from which $P$. sclerotioides was successfully isolated from the corresponding part of the plant by the total number of plants sampled.

Assessment of BRR severity. All roots and crowns were labeled before processing. Immediately after isolations were made, the labeled roots and crowns were placed in storage at $-17^{\circ} \mathrm{C}$. After the final assessment of culture identity was completed, the samples were removed from storage, and the severity of the lesions from which $P$. sclerotioides was successfully isolated was rated. The following scale was used: $0, P$. sclerotioides not successfully isolated from root or crown; 1 , lesions restricted to the epidermal tissues; 2 , lesions extend into the cortical tissues but affect $\leq 33 \%$ of root or crown diameter; 3 , lesions affect 34 to $66 \%$ of root or crown diameter; 4, lesions affect 67 to $99 \%$ of root or crown diameter; and 5, lesions completely girdle root or crown. BRR severity ratings were made separately for roots and crowns, and total BRR severity of individual plants was designated by assigning the more severe rating (root versus crown) to the plant.

Confirmation of pathogen identity. Diagnostic PCR. For every field from which $P$. sclerotioides was successfully isolated, morphological identification of at least one single-conidium $P$. sclerotioides culture was confirmed using $P$. sclerotioides-specific PCR-based SCAR markers (28). The culture subjected to the PCR test was arbitrarily selected from the single-conidium isolates collected from that field. Cultures were established on PDA, transferred to potato dextrose broth (PDB; Difco Laboratories), and grown for 3 to 5 weeks at $10^{\circ} \mathrm{C}$ under continuous white fluorescent light. After incubation, the cultures were centrifuged, the PDB decanted, and the mycelium rinsed twice in sterile distilled water. The mycelium was lyophilized, and DNA was extracted using a DNeasy Plant Mini Kit (Qiagen, Inc., Valencia, CA) according to manufacturer instructions. Diagnostic PCR was conducted in a PTC-100 Peltier Thermal Cycler (MJ Research, Waltham, MA). Each reaction included $14.375 \mu$ water, $0.25 \mu \mathrm{l}$ Qiagen Hot Star Taq (5 U/ $\mu \mathrm{l}), 0.5$ $\mu \mathrm{l}$ primer PSB12-FS-24 $(50 \mu \mathrm{M}), 0.5 \mu \mathrm{l}$ primer PSB12-RS-26 $(50 \mu \mathrm{M}), 0.25 \mu \mathrm{l}$ dNTPs $(10 \mathrm{mM}), 2.5 \mu$ l Qiagen 10× PCR buffer, and $2.5 \mu \mathrm{MgCl}_{2}(25 \mathrm{mM})$. The following thermocycler parameters were used: $2 \mathrm{~min}$ at $95^{\circ} \mathrm{C}$, followed by 35 cycles of $94^{\circ} \mathrm{C}$ for $1 \mathrm{~min}, 60^{\circ} \mathrm{C}$ for $1 \mathrm{~min}$, and $72^{\circ} \mathrm{C}$ for $1 \mathrm{~min}$, and a final extension of 1 min at $72^{\circ} \mathrm{C}$, followed by a $4^{\circ} \mathrm{C}$ bath. Positive and negative controls were included. The P. sclerotioides "Berg" isolate (American Type Culture Collection isolate MYA-295), isolated from a diseased alfalfa plant near Farson, WY, was used as a positive control; a no-template reaction was included as a negative control.
In vivo pycnidia and conidia characteristics. In vivo confirmation of pathogen identity was conducted by evaluating pycnidia and conidia produced in vivo on inoculated alfalfa. Six single-conidium isolates, two each from New York, Vermont, and New Hampshire, were used to inoculate "Multi-plier" alfalfa, a variety highly susceptible to BRR (18). Individual plants were started in SC10 Cone-Tainers (Stuewe and Sons, Inc., Corvallis, OR) in an autoclaved mix of 50\% sand and 50\% loam soil. Three to four seeds were placed in each pot, approximately $0.1 \mathrm{~g}$ of Dormal alfalfa Rhizobium inoculant (Becker Underwood, Ames, IA) was sprinkled over the seed, and the seed and inoculant were lightly covered with peat moss. Three weeks after seeding, plants were thinned to one plant per pot, with the most vigorous seedlings selected. Before inoculation, plants were grown for 5 months in the greenhouse at 25 to $35^{\circ} \mathrm{C}$, with a $200 \mathrm{ppm}$ solution of 21-5-20 fertilizer (96 g/liter) and Epsom salts (30 g/liter) applied monthly. Five months after seeding, the soil was removed from the first $3 \mathrm{~cm}$ of the root, two to four barley grains colonized by $P$. sclerotioides were placed against the root, and the soil was replaced. Barley grain inoculum was produced by growing $P$. sclerotioides on PDA in 100-mmdiameter petri dishes, covering the colonized PDA with autoclaved soaked barley, and incubating at $10^{\circ} \mathrm{C}$ under constant light for 8 to 10 weeks. Seven plants were inoculated with each isolate. Immediately after inoculation, plants were moved to growth chambers. To induce dormancy, they were maintained 2 weeks at $10^{\circ} \mathrm{C}$ with $16 \mathrm{~h}$ light/day, 2 weeks at $3^{\circ} \mathrm{C}$ with $16 \mathrm{~h}$ light/day, and 10 days at alternating temperatures $\left(20\right.$ to $21 \mathrm{~h}$ at $3^{\circ} \mathrm{C}$ and 3 to 4 $\mathrm{h}$ at $-17^{\circ} \mathrm{C}$ ) under complete darkness. To simulate winter and spring, plants were then kept 2 weeks in complete darkness at $-17^{\circ} \mathrm{C}, 8$ weeks at $3^{\circ} \mathrm{C}$ with $16 \mathrm{~h} \mathrm{light/day}$ and 4 weeks at $10^{\circ} \mathrm{C}$ with $16 \mathrm{~h}$ light/day. Finally, to ensure that all plants had emerged from dormancy before winterkill assessments were made, plants were kept at $25^{\circ} \mathrm{C}$ with $16 \mathrm{~h} \mathrm{light/day} \mathrm{for} 1$ week. The roots were harvested and washed, and pycnidia were collected from the roots. For each isolate, the diameter of 40 randomly selected pycnidia and length, width, guttule number, and guttule polarity of 40 randomly selected conidia were assessed with a compound microscope. Summary statistics (minimum, maximum, 10\% quantile, $90 \%$ quantile, and median) of the pycnidium and conidium size data were calculated in PROC MEANS (SAS, ver. 9.1, SAS Institute, Cary, NC), and pycnidial and conidial characteristics were compared to published descriptions of $P$. sclerotioides $(5,19)$.

Pathogenicity testing. The roots of the inoculated greenhouse- and chambergrown alfalfa (above) were thoroughly 
colonized by $P$. sclerotioides, with abundant pycnidia produced throughout. However, it was unclear whether the fungus colonized the roots pathogenically or saprophytically. All of the harvested roots were completely soft-rotted, and none of the plants emerged from dormancy, suggesting that the potted plants may have been killed by the $-17^{\circ} \mathrm{C}$ treatment. To test for pathogenicity, "Vernal" alfalfa, a variety susceptible to BRR (48), was planted at field sites in New York's Clinton and Steuben counties in spring 2006. Vernal was used because sufficient seed of Multi-plier was not available. Clinton County is in northeastern New York, Steuben County in south-central New York. Neither field had been previously assessed for BRR, but both fields were located on farms where BRR was detected in 2005. The Clinton Co. and Steuben Co. fields are located at $44^{\circ} 54^{\prime}$ and $42^{\circ} 15^{\prime}$ north latitude, respectively, and 60 and $510 \mathrm{~m}$ above sea level, respectively. Both sites receive ample spring and summer rainfall, and irrigation was not used. Five replicates, each consisting of five rows $1.4 \mathrm{~m}$ long and $0.25 \mathrm{~m}$ apart, were established at each site; one additional row and $0.3 \mathrm{~m}$ of row length were added to the edges of the plot as a border. In every row, $1.0 \mathrm{~g}$ of seed and $0.05 \mathrm{~g}$ of Rhizobium inoculant were used. Plots were seeded in the spring and thinned once in the early summer, selecting the most vigorous plants. Plants were weeded twice, and foliage was trimmed once in August. Plants were inoculated 26 September and 6 October at the Clinton Co. and Steuben Co. plots, respectively. Plants did not appear stressed. Barley grain inoculum was prepared by growing $P$. sclerotioides on PDA in petri dishes, covering the cultures with autoclaved soaked barley, and incubating under continuous light for 2 months at $10^{\circ} \mathrm{C}$. Single-spore isolates 'Chz5 9R' and 'StbI-1(2)17R', collected in 2005 from different fields on each respective farm, were used for the Clinton Co. and Steuben Co. plots, respectively. Soil was carefully removed from one side of the roots, barley grain inoculum was placed against the upper tap root 3 to $6 \mathrm{~cm}$ below the crown, and the soil was replaced. Four of the five rows in each replicate were inoculated; the fifth was not. Twelve plants, approximately three from the end of each inoculated row, were collected in each replicate (a total of 60 plants/plot) on 2 December in Clinton Co. and 3 December in Steuben Co. The soil was not frozen at either site. Plants were stored at $3^{\circ} \mathrm{C}$ until processing; all samples were processed within a week of collection. Plants were washed vigorously, and root and crown rot severity was rated for each plant using an ordinal scale from 0 to 5 (as above). Root and crown segments were excised from all plants, surface sterilized, plated on water agar, and incubated under continuous light at $10^{\circ} \mathrm{C}$ for 9 weeks. After incubation, tissue segments and surrounding agar were examined under a compound scope for the beaked pycnidia characteristic of $P$. sclerotioides. When pycnidium morphology was ambiguous, pycnidia were harvested and used to establish single-conidium cultures on PDA. The single-conidium cultures were incubated under continuous light at $10^{\circ} \mathrm{C}$ for 4 weeks, and culture identity assessed. Single-conidium cultures were also established from arbitrarily selected pycnidia characteristic of $P$. sclerotioides. Only lesions from which $P$. sclerotioides was successfully isolated were considered to be BRR.

Evaluation of spring regrowth. Before tissue segments were excised from plants collected in the BRR survey for P. sclerotioides isolation, the spring regrowth was evaluated for a subset of the collected plants in the two extensively sampled fields. The plants collected at 21 of the 23 sampled sites in field Wyol and 20 of the 24 sampled sites in field Chz1 were subjected to analysis; the sampling sites represented in the analysis were chosen randomly. Shortly after the plants were collected, the roots were labeled. The spring regrowth, including both stems and leaves, was removed from each plant approximately $1 \mathrm{~cm}$ above the crown and placed into a correspondingly labeled coffee filter. All dry stems and other debris from previous seasons were separated and discarded. The labeled roots were returned to refrigeration for subsequent pathogen isolation. The labeled coffee filters were stacked, stapled together to prevent spillage, placed in small paper bags, and dried at $50^{\circ} \mathrm{C}$ for 5 days. Immediately after removing samples from the drier, the dry weight of spring regrowth was recorded to the nearest $0.01 \mathrm{~g}$. The relationship between BRR severity and spring regrowth of individual plants was assessed with least-squares regression. Because of very small sample sizes for the most severe disease severity category, the two highest disease severity categories (BRR severity 4 and 5) were pooled for the analysis. Regression was conducted in PROC GLM (SAS, ver. 9.1) with BRR severity as a categorical independent variable. Assumptions of least-squares regression were assessed, and the square root transformation was applied to spring regrowth to stabilize the variance of the residuals and normalize the distribution of the residuals.

Stand density. In the Wyoming and Clinton county fields where extensive sampling was conducted, the relative stand density at the various sampling locations was recorded when the plants were collected. Locations where plant density was less than approximately four plants $/ \mathrm{m}^{2}$ were noted as having low stand density.

Soil analysis. In the extensively sampled Wyoming and Clinton county fields, soil characteristics were analyzed at all sampling sites. Soil cores were collected in the center of the sampling location, and loose soil was obtained from around the roots as they were sampled. The soil cores (height $7.6 \mathrm{~cm}$, internal diameter $7.6 \mathrm{~cm}$ ) were taken from just below the soil surface. Two cores and one core were collected from each sampling site in fields Chz1 and Wyo1, respectively. The intact cores were placed in plastic bags and stored at $3{ }^{\circ} \mathrm{C}$ until processing. The loose soil was collected in plastic bags, dried on a greenhouse bench, and stored at $3^{\circ} \mathrm{C}$ until processing.

Percent clay and particulate organic matter. Percent clay and particulate organic matter (POM) of the soil samples were analyzed with a protocol adapted from Kettler et al. (24). The air-dried loose soil samples were crushed into a fine powder with a large pestle. A subsample of each crushed soil sample was passed through a 2-mm sieve to remove rocks and debris and dried at $100^{\circ} \mathrm{C}$ for approximately $24 \mathrm{~h}$. For each sample, $30 \mathrm{~g}$ of soil was transferred to a $125-\mathrm{ml}$ wide-mouth bottle, and $90 \mathrm{ml}$ of an aqueous $0.5 \%$ sodium polyphosphate (Sigma-Aldrich) solution was added. Samples were shaken vigorously and placed on a reciprocating shaker (180 reciprocations/min) for approximately 16 h. After dispersion, the samples were passed through a $0.053-\mathrm{mm}$ mesh sieve to separate sand $(>0.053 \mathrm{~mm})$ and POM from silt and clay. Sand and POM were dried at $100^{\circ} \mathrm{C}$ to constant weight, weighed to the nearest $0.01 \mathrm{~g}$, and heated at $450^{\circ} \mathrm{C}$ overnight to assess POM by loss on ignition (LOI; 6). The soil slurry that passed through the $0.053-\mathrm{mm}$ sieve was transferred to 1.2-liter sedimentation cylinders. Water was added to bring the solution volume to 1.13 liters, the cylinder was capped and inverted multiple times to fully mix the contents, and the uncapped cylinder was left undisturbed for $24 \mathrm{~h}$. After 24 $\mathrm{h}$, the unsedimented clay suspension was suctioned into weigh containers, dried at $100^{\circ} \mathrm{C}$ to constant weight, and weighed to the nearest $0.01 \mathrm{~g}$. The sedimented portion (silt) was also transferred to weigh containers, dried at $100^{\circ} \mathrm{C}$ to constant weight, and weighed to the nearest $0.01 \mathrm{~g}$. Clay and POM (by LOI) content were calculated by dividing their calculated weights by the sum of the calculated weights of POM, sand, clay, and silt. Because LOI overestimates soil organic matter content (6), percent POM was corrected with a routine formula employed by the Cornell University Nutrient Analysis Laboratory:

$\% \mathrm{POM}_{\text {corrected }}=\left(\% \mathrm{POM}_{\text {by LOI }} * 0.7\right)-0.23$ (1)

Soil texture analysis to assess clay and POM content was conducted twice for each sampling location, and results were averaged over the two repetitions. The accuracy of the results for clay content was evaluated by sending six of the soil samples, crushed and sieved as described, to 
the Cornell Nutrient Analysis Laboratory (Cornell University, Ithaca, NY) for soil texture analysis using the pipette method (12), a standard method of particle-size analysis. Results from the two methods were compared by conducting linear regression with PROC REG (SAS, ver. 9.1). Because the sample sizes were small and it was reasonable to conclude that both methods would yield values very close to $0 \%$ clay if no clay were present, the intercept was forced to zero in the analysis. The regression yielded the models $y=0.919 x, y$ $=0.825 x$, and $y=0.872 x$ for repetition 1 , repetition 2 , and the average of repetitions 1 and 2 of the soil texture analysis, respectively, where $x$ represents the results from the pipette method. The coefficients of correlation for the tests were $0.992(n=6)$, $0.982(n=6)$, and $0.990(n=6)$, respectively.

Soil strength and relative saturation. The strength and relative saturation of the soil, measures of compaction and wetness, respectively, were assessed using the soil cores. The relative saturation of field-moist soil cores, not the relative saturation of the cores at a controlled matric potential, was used for analysis because it more realistically represents the variability in soil moisture observed in the fields, both of which had pronounced low spots and high spots. Soil cores were gently trimmed to volume, two layers of cheesecloth were fastened over the bottom of the cores with a rubberband, and field weight of the cores was determined to the nearest $0.1 \mathrm{~g}$. Cores were placed in a basin, gradually wetted from the bottom, and soaked for 2 days. The weight of the saturated cores was recorded, and the cores were transferred to a custom-made sand tension table controlled with vacuum pressure regulators (47) to adjust the matric potential. Wet soil samples were placed atop $0.42-\mu \mathrm{m}$ nylon filter membranes that rest on fine sand. The pressure in the sand bed was reduced to $-10 \mathrm{kPa}$ for 1 day, drawing water out of the soil cores until hydraulic equilibrium was established (25). Controlling the water potential of soil samples was required for meaningful comparisons of soil strength due to the strong dependence of measured soil strength values on water status. After matric potential equilibration, a micropenetrometer consisting of a $30^{\circ}$ angle cone with a 4-mm-diameter base soldered to a 2-mm-diameter stainless steel rod was driven into the top of each soil core at a rate of $10 \mathrm{~mm} \mathrm{~s}^{-1}$ for 4 to $8 \mathrm{~s}$ using a modified drill press. The resistive force to the insertion was recorded to the nearest gram each second via the serial output from the balance to a Microsoft Excel spreadsheet using data acquisition software (WinWedge 3.0, TALtech, Philadelphia, PA). To avoid edge effects, the penetrometer was pushed 5 to $10 \mathrm{~mm}$ into the sample before resistance measurements were started. For each core, penetrometer readings were taken at three locations. If the penetrometer encountered a rock, the reading was discarded and replaced with a new reading. Penetration resistance of each core was averaged and converted to pressure units (MPa) by multiplying the penetration resistance by the force of gravity $\left(9.8 \mathrm{~m} \mathrm{~s}^{-2}\right)$ and dividing by the penetrometer area $(\pi *$ $0.002^{2} \mathrm{~m}^{2}$ ). The soil cores were then dried at $100^{\circ} \mathrm{C}$ to constant weight and weighed to the nearest $0.1 \mathrm{~g}$. Total porosity was estimated by dividing the volumetric water content of the saturated soil core (in $\mathrm{cm}^{3}$ ) by the volume of the soil core (in $\mathrm{cm}^{3}$ ); volumetric water content of the saturated soil core was found by subtracting the oven-dry core weight from the saturated core weight and dividing by the oven-dry core weight and multiplying by the dry bulk density. All pore spaces were assumed to be completely filled with water in the saturated core and completely drained in the oven-dry core. The original field water content of the soil was estimated by subtracting the oven-dry soil core weight from the field-moist core weight and dividing the difference by soil core volume. Relative saturation was calculated by dividing original field water content of the soil (in $\mathrm{cm}^{3}$ ) by total porosity of the soil $\left(\right.$ in $\mathrm{cm}^{3}$ ). Results from the two soil cores collected at each site in the Clinton County field were averaged.

Distribution of BRR within fields. Topographical maps. The spatial pattern of BRR incidence within the sampled areas of fields Wyo1 and Chz1 was mapped with Surfer (ver. 8.0, Golden Software, Golden, $\mathrm{CO}$ ). The $60 \times 100 \mathrm{~m}$ and $180 \times 300 \mathrm{~m}$ sampling grids of fields Wyo1 and Chz1, respectively, were plotted within the first quadrant of a Cartesian plane, with the origin representing the approximate southeast corner of each sampling grid, the $x$ and $y$ axes representing the approximate southern and eastern edges of the grids, and each unit along the axes representing 1 $\mathrm{m}$. Analogous maps were created to illustrate the spatial pattern of soil characteristics in the fields. Sampling locations with low stand density were marked with asterisks on the BRR incidence map. The machinery entry point to field Wyol corresponds to point $(100,60)$; entry points to field Chz1 correspond to points $(0,0)$ and $(0,60)$.

Spatial structure. As a preliminary test of BRR spatial structure, contingency tables with the dichotomous response BRR (present or absent) and nominal response sampling site (1 to 23 or 24 ) were constructed, and chi-square analysis testing the null hypothesis that frequency of BRR is uniform across sampling locations was conducted using PROC FREQ (SAS, ver. 9.1). However, because chi-square analysis of contingency tables does not incorporate spatial components into the analysis, it cannot evaluate positive autocorrelation (aggregation). To overcome this limitation, two tests of autocorrelation, Mantel statistics and Spatial Analysis by Distance IndicEs (SADIE), were also conducted. Both tests utilize permutation approaches to assess statistical significance and can be used with smaller sample sizes than comparable tests that assume an underlying normal distribution for assessing significance. Mantel tests can be used with sample sizes as small as $20(10)$, and both tests have been used to successfully detect autocorrelation in sample sizes as small as 12 (43). Counts of BRR-positive plants per sampling location, the variable traditionally related to spatial location in ecological applications of Mantel and SADIE tests, could not be used because the total number of plants sampled differed across sampling sites within the fields; instead, as suggested by Perry et al. (38) for SADIE tests, percent BRR-positive plants, rounded to the nearest integer, was used.

The Mantel test evaluates the correlation between two $n \times n$ distance matrices; in this study, one matrix represented the differences in spatial distances and the other, differences in the frequency of BRR among all possible pairs of sampling sites. To produce the normalized Mantel statistic $(r)$, the standard normal transformation is applied to each matrix, the products of corresponding elements of the matrices are summed, and the sum is divided by $N-1$, as follows:

$$
\begin{array}{r}
r=\left\{\sum_{i=1}^{n} \sum_{j=1}^{n}\left[\left(x_{i j}-\bar{X}\right) / s_{x}\right]\left[\left(y_{i j}-\bar{Y}\right) / s_{y}\right]\right\} /(N-1) \\
\text { for } i \neq j
\end{array}
$$

where $i$ and $j$, respectively, denote matrix rows and columns 1 to $n$, and $N$ represents the number of distances, excluding the diagonal, in one of the matrices $(10,32)$. The resulting test statistic ranges from -1 to 1 , with values closer to 0 less likely to result in a rejection of the null hypothesis that the two distance matrices are uncorrelated. Significance of the test statistic is determined with permutation techniques; one of the two matrices is permuted randomly, and $r$ is computed with the various permutations, producing a set of values of $r$ used to represent the sampling distribution of $r$ under $\mathrm{H}_{0}$ (32). An SAS Program (SAS, ver. 9.1) written by Edgar Barry Moser (Louisiana State University, Baton Rouge; available online from the LSU Department of Experimental Statistics) was used for the analysis.

SADIE describes ecological spatial structure by relating spatial pattern in a population to the minimum total movement required for individuals in that population to reach a completely uniform distribution (38). To establish a uniform distribution, individuals must be moved either from sources (points with more individuals than the mean) to sinks (points with fewer individuals than the mean) or, equivalently, from sinks to sources. The 
total distance that individuals in the population would need to move in order to establish a completely uniform distribution is denoted as total flow distance, $D$ :

$$
D=\sum_{i=1}^{p} \sum_{j=1}^{q} v_{i j} d_{i j}
$$

where $p=$ number of sampling locations with counts above the mean (sources), $q=$ number of locations with counts below the mean (sinks), $i=$ source locations 1 to $p, j$ $=$ sink locations 1 to $q, v_{i j}=$ number of individuals flowing from source location $i$ to sink location $q$, and $d_{i j}=$ distance between source location $i$ and sink location $j$ (8). The minimum total flow distance, $D_{r}$ (distance to regularity), is developed by an algorithm, and permutation techniques are used to evaluate the probability of observing that distance by chance. The sample is permuted randomly, $D_{r}$ is calculated for each permutation, and the resulting set of $D_{r}$ values is used to construct a sampling distribution for testing the significance of the observed distance. Total aggregation of the sample is represented by an index of aggregation, $I_{a}$, calculated by dividing the observed distance to regularity by the mean minimum distance to regularity of the permutations of the sample, with values of $I_{a}<1,=1$, and $>1$ suggesting uniform, random, and aggregated patterns, respectively (36). SADIEShell (version 1.22, J. N. Perry, Rothamsted Research, Hertfordshire, UK; available online from Rothamsted Research) was used for the analysis.

Cumulative logistic regression. The distribution of BRR in both of the extensively sampled fields was nonuniform, and a proportional odds model was used to assess if variations in soil characteristics and stand density were significant explanators of BRR distribution. The proportional odds model is a logistic regression technique applicable for data with an ordinal response variable. It models several cumulative log-odds, one for each cut point in the polytomous response (i.e., BRR severity 5 versus $4,3,2,1,0$; BRR severity 5,4 versus $3,2,1,0$; etc.), fitting different intercepts for each cumulative log-odds but constraining the regression parameters of the independent variables to be equal across all cut points $(21,44,46)$ :

$$
\log \operatorname{it}\left(\theta_{k}\right)=a_{k}+\sum_{g=1}^{t} \beta_{g} x_{g}+\varepsilon
$$

for dichotomous and continuous independent variables, where $k$ represents levels 1 , $2, \ldots, k$ of the dependent variable; logit $\left(\theta_{k}\right)$, the cumulative log-odds for level $k$ of the dependent variable; $\alpha_{k}$, the intercept for level $k ; g$, independent variables 1,2 , $\ldots, t ; \beta_{g}$, the regression parameter for independent variable $g$; and $\varepsilon$, error. Maximum likelihood is used to estimate the parameter values $(1,46)$. PROC LOGISTIC (SAS, ver. 9) was used for the analysis. A model with independent variables percent clay, percent soil organic matter, stand density, soil strength, and relative soil saturation was fit for each field, and all possible combinations of interactions and second-order nonlinearities were tested. Significant interactions $(P<0.05)$ were added to the model; none of the nonlinearities were significant. Overdispersion, a product of the sampling design, was a problem in both models. Because modifying the model by adding interaction terms or nonlinearities did not resolve the problem, overdispersion was addressed by using the ratio of the Pearson goodness-offit chi-square to its degrees of freedom to scale the standard errors and chi-square values of the parameter estimates (1). The proportional odds assumption was assessed with the score test produced by SAS $(1,44)$ and confirmed by conducting binary logistic regression separately for each cut-point of the dependent variable, estimating point estimates and $95 \%$ confidence intervals of the binary log-odds ratios corresponding to each cut-point, and assessing whether the point estimates for each model were within the corresponding confidence intervals of the other models (44). The proportional odds assumption was not met when BRR severity levels had small sample sizes $(n \leq$ 7). To meet the model assumptions, BRR severity levels 3, 4, and 5 were pooled for the Wyoming County field, and levels 4 and 5 were pooled for the Clinton County field.

Correlation analysis. The results of the logistic regression were corroborated by conducting simple correlation analysis.
Pearson's correlation coefficient was calculated in PROC CORR (SAS, ver. 9) for the relationship between BRR incidence and clay and POM content, soil saturation, and soil strength.

\section{RESULTS}

Distribution, incidence, and severity of BRR. $P$. sclerotioides was successfully isolated from alfalfa roots and/or crowns from 8 of 10 alfalfa production fields surveyed in New York, 6 of 7 fields surveyed in Vermont, and 5 of 6 fields surveyed in New Hampshire (Table 1), including fields from both western and northern New York and both central and northern Vermont and New Hampshire (Fig. 1). Among fields from which $P$. sclerotioides was isolated, BRR incidence ranged from 4 to $67 \%$ in New York, 5 to $51 \%$ in Vermont, and 3 to $40 \%$ in New Hampshire (Fig. 1). Both root and crown BRR lesions were common in all three states, and $P$. sclerotioides was successfully isolated from both roots and crowns in all but two of the fields where BRR was detected. In most fields, the frequency of root versus crown BRR lesions was approximately equal; however, root lesions were much more prevalent in three fields, and crown lesions were much more prevalent in one field (Table 1). In all fields sampled, at least half of the lesions from which $P$. sclerotioides was isolated extended into the cortical tissues (Table 1).

Confirmation of pathogen identity. Diagnostic PCR resulted in amplicons of the expected size (approximately $500 \mathrm{bp}$ ) for both the positive control (the P. sclerotioides "Berg" isolate from Farson, WY,

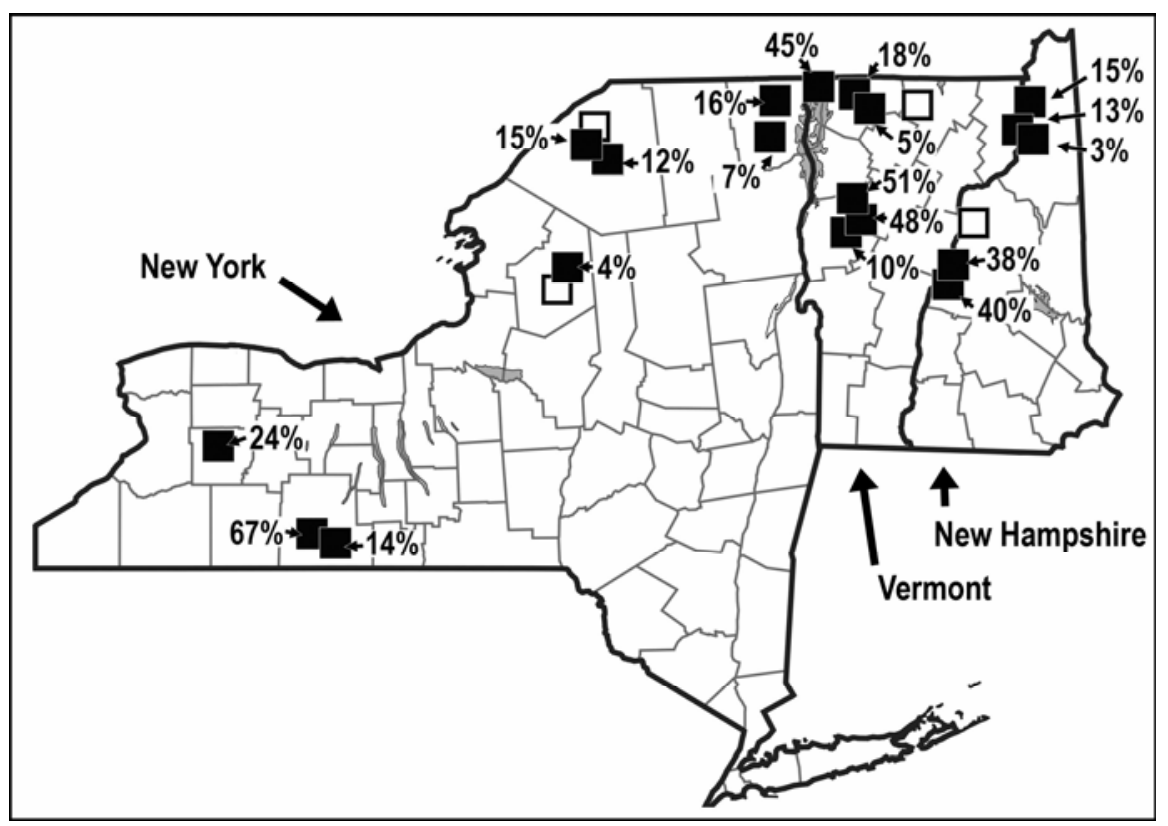

Fig. 1. Distribution and incidence of brown root rot (BRR) in New York, Vermont, and New Hampshire alfalfa production fields sampled in spring 2005. Filled boxes denote fields where Phoma sclerotioides was successfully isolated from at least one root and/or crown; empty boxes represent fields where P. sclerotioides was not successfully isolated. Percentages indicate BRR incidence; plants were considered positive for BRR only if $P$. sclerotioides was successfully isolated from the root and/or crown. Approximately 40 plants, selected randomly without regard to vigor or apparent health, were collected from most fields. 
USA; American Type Culture Collection isolate MYA-295) and at least one randomly selected single-conidium $P$. sclerotioides isolate from each of the fields from which the pathogen was successfully isolated. The negative control (no template) resulted in no amplification product. In vivo on roots of greenhouse- and growth chamber-grown alfalfa, New York, New Hampshire, and Vermont P. sclerotioides isolates produced pycnidia with diameters from 300 to $850 \mu \mathrm{m}$ and conidia with lengths from 4 to $8 \mu \mathrm{m}$ and widths from 1.5 to $4 \mu \mathrm{m}$ (Fig. 2). Conidia guttule number ranged from 0 to 4 , and most ( $>97 \%$ ) conidia had polar guttules. Pathogenicity testing at field sites in New York's Clinton and Steuben counties resulted in reddishbrown to dark-brown epidermal lesions and light- to dark-brown lesions progressing into the cortical tissues. The lesions developed at the site where inoculum was placed against the root. However, P. sclerotioides was isolated from both lesioned and nonlesioned roots. Nine weeks after plating surface-sterilized root segments onto water agar, abundant beaked pycnidia characteristic of $P$. sclerotioides were produced in the agar or directly on root segments. In the Clinton County plot, P. sclerotioides was isolated from 37 of 60 plants, of which 14 showed no lesions, 20 had epidermal lesions, and three had lesions progressing into the cortex. In the Steuben County plot, $P$. sclerotioides was isolated from 20 of the 60 plants, of which three showed no lesions, 15 had epidermal lesions, and two had lesions extending into the cortex. Single-conidium cultures established on PDA from pycnidia harvested from water agar plates were characteristic of $P$. sclerotioides.

Evaluation of alfalfa spring regrowth. Spring regrowth of individual plants varied widely, particularly when BRR severity levels were low, and zero or near-zero spring regrowth was observed for plants at all BRR severity levels (Fig. 3). Linear regression of BRR severity (with severity levels 4 and 5 pooled because of small sample sizes) against the dry weight of spring regrowth (subjected to the squareroot transformation to meet model assumptions) yielded correlation coefficients of $0.0125(n=615)$ and $0.0079(n=628)$ for the Wyoming and Clinton county fields, respectively. Evaluation of the null hypothesis that spring regrowth was unrelated to BRR severity resulted in $F$ values of 1.92 and 1.23 with 4 degrees of freedom and corresponding $P$ values of 0.1045 and 0.2955. For field Wyo1 (Wyoming County), contrasts between the highest BRR severity level (4, lesions affect $\geq 67 \%$ of root and/or crown diameter) and other BRR severity levels indicated a significant $(P<0.05)$ or marginally significant $(P=$
0.0676) decrease in spring regrowth for plants with BRR severity 4 relative to plants with BRR severity 0,1 , and 2 , but not 3 (Table 2). For field Chz1 (Clinton County), contrasts between the highest BRR severity level (4, lesions affect $\geq 67 \%$ of root and/or crown diameter) and other BRR severity levels indicated no significant decrease in spring regrowth $(P>0.05)$ for plants with BRR severity 4 relative to plants with BRR severity $0,1,2$, or 3 (Table 2).

Distribution of BRR within fields. Among the 17 fields sampled at four sites each, BRR was not detected in three fields. In the remaining 14 fields, BRR was detected at one of the sampling sites in one field, at two of the sampling sites in four
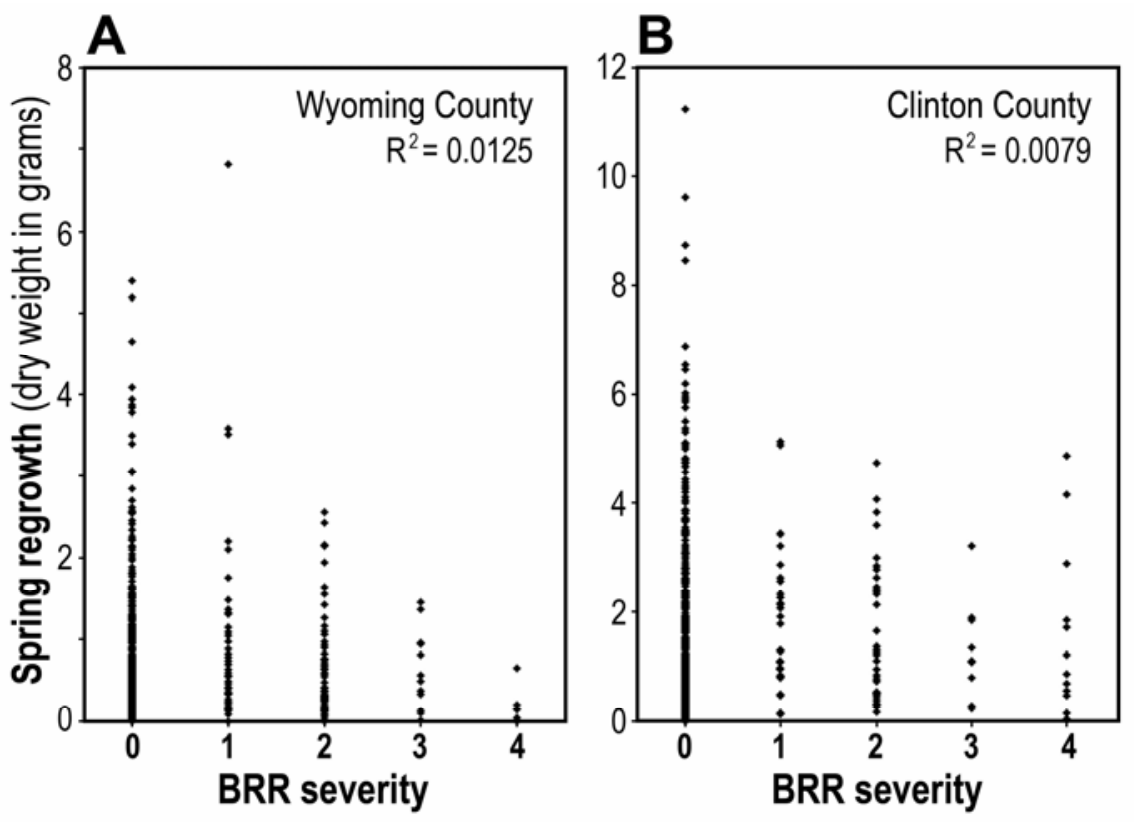

Fig. 3. Scatter plots of spring regrowth (dry weight in grams) of individual alfalfa plants with brown root rot (BRR) severity of 0 (Phoma sclerotioides not successfully isolated from the root or crown), 1 (P. sclerotioides isolated; lesions epidermal), 2 (P. sclerotioides isolated; lesions extend into cortex but affect $\leq 33 \%$ of root or crown diameter), 3 (P. sclerotioides isolated; lesions affect between 34 and $66 \%$ of root or crown diameter), and 4 ( $P$. sclerotioides isolated; lesions affect $\geq 67 \%$ of root or crown diameter) in the extensively sampled fields A, Wyoming County, NY, and B, Clinton County, NY.

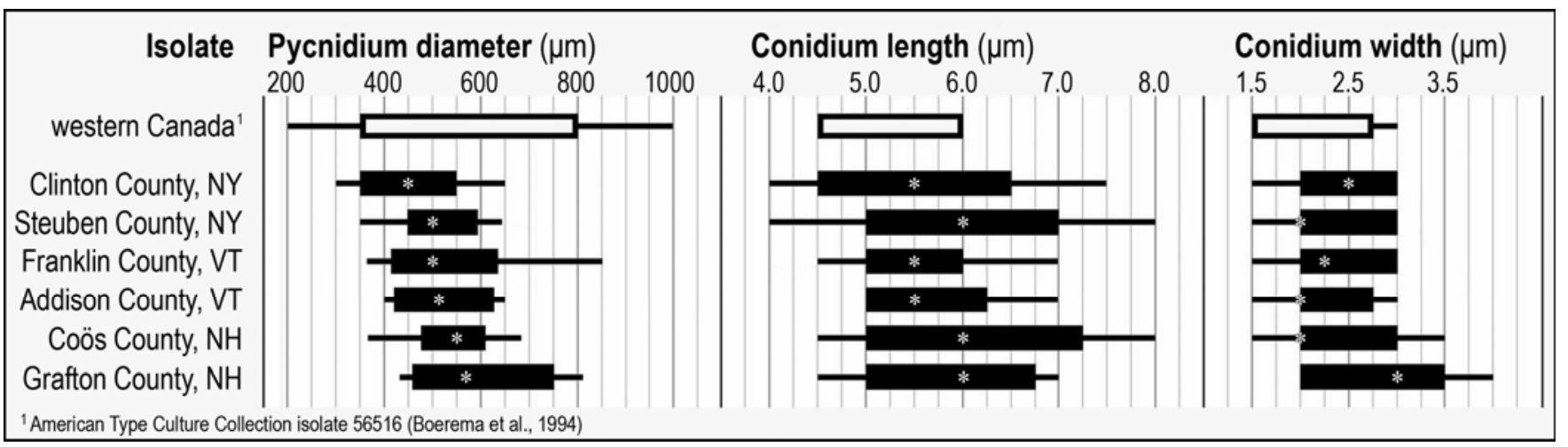

Fig. 2. In vivo pycnidium and conidium sizes of single-conidium Phoma sclerotioides isolates from New York, Vermont, and New Hampshire compared to the published description of the species. For northeast U.S. isolates, extent of thin bars corresponds to minimum and maximum values, extent of thick bars corresponds to 10 and $90 \%$ quantiles, and asterisks correspond to median values of 40 randomly selected pycnidia and 40 randomly selected conidia. Values for isolate from western Canada are taken from Boerema et al. (5); extent of thin lines represents minimum and maximum values, and boxes represent the most common values. 
fields, at three of the sampling sites in one field, and at all four sampling sites in eight fields. In the two fields (Wyo1 and Chz1) sampled at 23 to 24 sites each, the highest BRR incidence was not observed at the machinery entry points to the fields, and gradients of decreasing BRR incidence from the machinery entry points were not observed (Fig. 4). The chi-square test and SADIE both indicated that the observed distribution of BRR within fields Wyol and Chz1 was random, not uniform; likewise, the Mantel test and SADIE both concluded that the distribution of BRR was random, not aggregated (Table 3 ).

Stand density. In the extensively sampled fields Wyo1 and Chz1 (seeded in 2001), 5 of 23 and 10 of 24 sampling sites, respectively, had low alfalfa stand densities (Fig. 4).

Soil characteristics. Clay and POM content varied widely across sampling sites in field Chz1 but varied little across sampling sites in field Wyo1 (Table 4); six different soil types were represented in the Clinton County field, and only one soil type was represented in the Wyoming County field (Table 4). Soil strength varied widely in both fields, but it was more variable in field Wyol than field Chz1 (Table 4); heavy compaction by farm equipment was observed on one end of the Wyoming County field but not observed in the Clinvaried moderately across sampling sites in field Chz1 but was somewhat less variable in field Wyo1 (Table 4). Both fields exhibited topographic variation, with low spots where water collected and high spots where water drained more readily. However, topographic variability was greater in the Clinton County than in the Wyoming County field.

Cumulative logistic regression indicated that, controlling for the other variables in ton County field. Relative soil saturation

the model, relative saturation, stand density, clay content, and soil strength were all significant $(P<0.05)$ or marginally significant $(P<0.08)$ explanators of the observed variability in BRR incidence and severity within the Wyoming and Clinton county fields (Table 5). In both fields, the odds of more severe BRR increased as relative soil saturation increased, and they decreased as alfalfa stand density decreased (Table 5). However, the effects of percent clay and of soil strength on BRR severity varied by field. In Clinton County, the odds of more severe BRR decreased as soil clay content increased. In Wyoming County, the odds of more severe BRR increased as soil clay content increased, but only among sites with low alfalfa stand density; across the entire field, no significant relationship was detected (Table 5). In Wyoming County, the odds of more severe BRR decreased as soil strength increased. In Clinton County, the odds of more severe BRR increased as soil strength increased, but only among sites with low stand density; across the entire field, no significant relationship was detected (Table 5). The likelihood ratio test of the overall significance of the regression models resulted in $P$ values of 0.0077 and 0.0250 for the Wyoming and Clinton county fields, respectively.

Maps illustrating the spatial distribution of BRR incidence, stand density, and soil characteristics show similar trends (Fig. 4). A general tendency for areas of low stand density to have lower BRR incidence, at least relative to the adjacent sampling sites, can be seen for both fields (Fig. 4, maps A and F; points with low stand density marked with asterisks), although it is somewhat less pronounced for the Wyoming County field than the Clinton County field. A negative relationship between percent clay and BRR incidence was evident

Table 2. Parameter estimates of the least-squares regression models assessing the relationship between brown root rot (BRR) severity and square-root transformed spring regrowth (dry weight in grams) ${ }^{\mathrm{a}}$

\begin{tabular}{|c|c|c|c|c|}
\hline Field & Variable $^{b}$ & $\begin{array}{c}\text { Parameter } \\
\text { estimate }^{c}\end{array}$ & $\begin{array}{c}\text { Standard } \\
\text { error }\end{array}$ & $P$ value \\
\hline Wyoming County, NY & $\begin{array}{l}\text { Intercept } \\
\text { BRRsev } 0 \\
\text { BRRsev } 1 \\
\text { BRRsev } 2 \\
\text { BRRsev } 3 \\
\text { BRRsev } 4\end{array}$ & $\begin{array}{l}0.3353 \\
0.3922 \\
0.4645 \\
0.3567 \\
0.2505 \\
0.0000\end{array}$ & $\begin{array}{c}0.1871 \\
0.1883 \\
0.1972 \\
0.1948 \\
0.2176 \\
*\end{array}$ & $\begin{array}{c}0.0736 \\
0.0377 \\
0.0188 \\
0.0676 \\
0.2502 \\
*\end{array}$ \\
\hline Clinton County, NY & $\begin{array}{l}\text { Intercept } \\
\text { BRRsev } 0 \\
\text { BRRsev } 1 \\
\text { BRRsev } 2 \\
\text { BRRsev } 3 \\
\text { BRRsev } 4\end{array}$ & $\begin{array}{l}1.0561 \\
0.0005 \\
0.2208 \\
0.1092 \\
0.0008 \\
0.0000\end{array}$ & $\begin{array}{c}0.1570 \\
0.1589 \\
0.1911 \\
0.1832 \\
0.2319 \\
*\end{array}$ & $\begin{array}{c}<0.0001 \\
0.9976 \\
0.2484 \\
0.5514 \\
0.9971 \\
*\end{array}$ \\
\hline
\end{tabular}

a More than 600 plants were evaluated in each field.

b BRRsev 0, 1, 2, and 3 are dummy variables for BRR severity, where 0 indicates Phoma sclerotioides not detected; 1, P. sclerotioides detected, BRR lesions epidermal; 2, P. sclerotioides detected, BRR lesions extend into cortex but affect $\leq 33 \%$ of root or crown diameter; 3 , P. sclerotioides detected, BRR lesions affect between 34 and $66 \%$ of root or crown diameter; and 4, P. sclerotioides detected, BRR lesions affect $\geq 67 \%$ of root or crown diameter.

c Each of the parameter estimates for the dummy variables BRRsev 0,1,2, and 3 represents a comparison between that particular BRR severity level and the highest severity level, BRRsev 4. in the Clinton County field $\left(r^{2}=-0.31, n=\right.$ $24)$, and a strong positive relationship between percent clay and BRR incidence existed among the sampling sites with low stand density in the Wyoming County field $\left(r^{2}=0.89, n=5\right)$. A negative relationship between soil strength and BRR incidence was evident in the Wyoming County field $\left(r^{2}=-0.32, n=23\right)$, and a positive relationship between soil strength and BRR incidence existed among sampling sites with low stand density in the Clinton County field $\left(r^{2}=0.59, n=10\right)$. Finally, a weak correlation between soil saturation and BRR incidence existed for the Wyoming County field $\left(r^{2}=0.20, n=23\right)$. No correlation, however, was observed between soil saturation and BRR incidence in the Clinton County field $\left(r^{2}=-0.01, n=\right.$ 24). All soil variables identified as nonsignificant explanators of BRR severity by logistic regression (Table 5) also showed low correlation with BRR incidence $\left(r^{2} \leq\right.$ $0.10)$.

\section{DISCUSSION}

The combination of identification of all isolates on three types of agar, in vivo assessment of morphological characteristics of the fungus, diagnostic PCR, and pathogenicity testing confirmed that $P$. sclerotioides is prevalent in alfalfa fields in New York, Vermont, and New Hampshire. Although the conidia produced on inoculated alfalfa roots by isolates from the Northeast were somewhat larger than those described by Boerema et al. (5), similarly large conidia have also been reported from the state of Wyoming (19), and other characteristics of the isolates in vivo, such as conidial guttule number and polarity and pycnidial diameter, were consistent with published descriptions of the pathogen $(5,19)$. The predominance of epidermal lesions in pathogenicity testing was not surprising. The plants were collected in early December, before the ground froze and just 2 months after inoculation, and previous researchers $(7,42)$ have observed that BRR lesions develop primarily in the late winter and early spring. Likewise, reisolation of $P$. sclerotioides from inoculated alfalfa roots with no visible lesions supports previous research suggesting that the pathogen can be harbored by roots lacking symptoms (41).

The results from the spring 2005 survey of New York, Vermont, and New Hampshire alfalfa production fields suggest that BRR is widespread in the region and that the disease may be economically important. Moderate (10 to 24\%) and high (38 to $67 \%$ ) BRR incidence was observed in many fields. A majority of the lesions associated with $P$. sclerotioides extended into the cortical tissues, suggesting that BRR may negatively impact root function and overall plant vigor in the region. Finally, BRR lesions were common on crowns as well as roots, suggesting that BRR may 

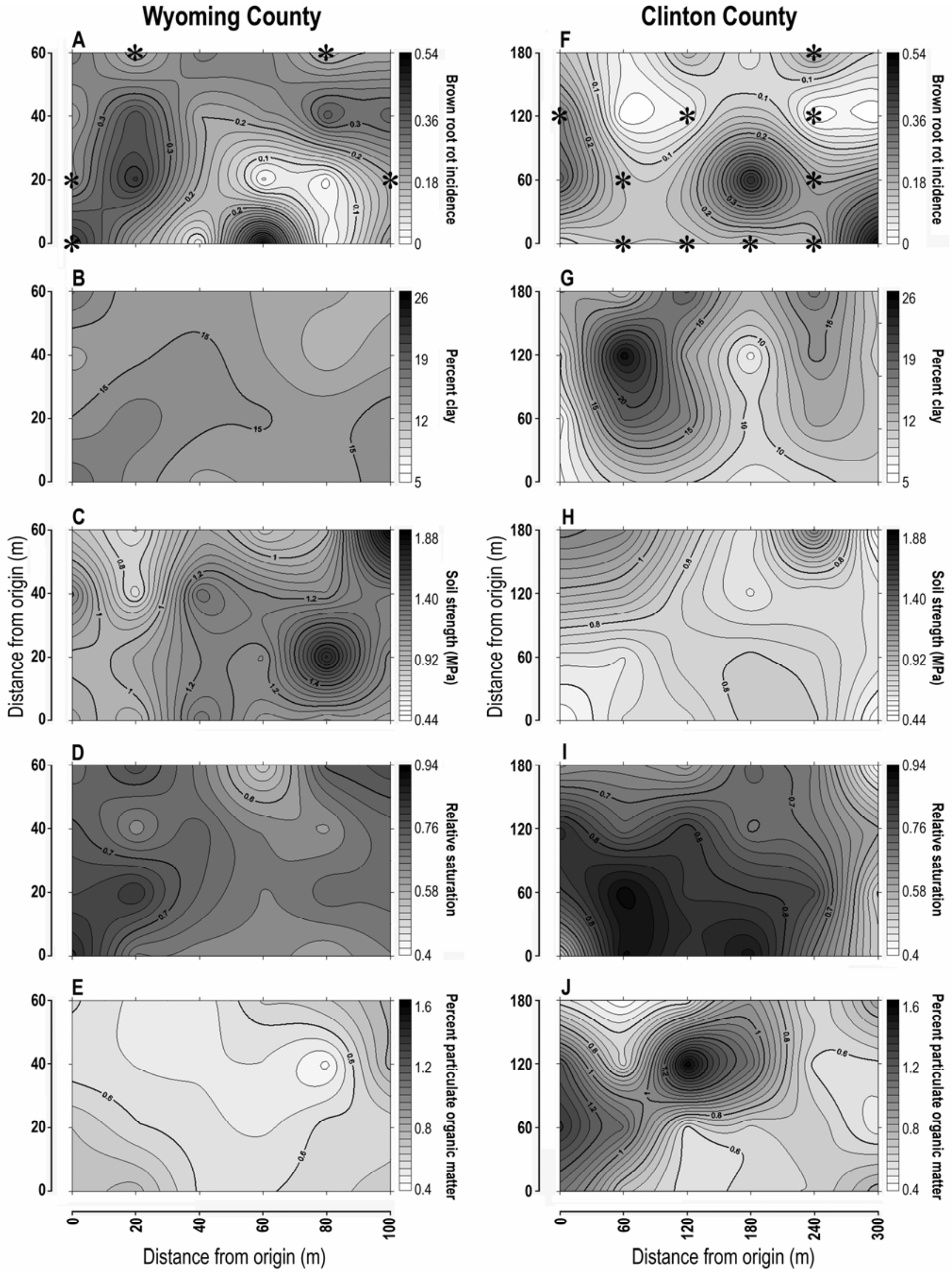

Fig. 4. Contour maps of spatial patterns of brown root rot incidence, stand density, and soil characteristics in two New York alfalfa production fields. Contour maps A to E, Wyoming County field; maps F to J, Clinton County field; asterisks refer to sampling sites where alfalfa stand density was low. Entry point for machinery into Wyoming County field corresponds to point $(100,60)$ on the Cartesian plane of the respective maps; entry points into Clinton County field correspond to points $(0,0)$ and $(0,60)$. Approximately 30 plants were collected from each of 23 or 24 sites on an equidistant grid; only 23 sites were sampled in Wyoming County field because plants collected at point $(40,20)$ were accidentally left in the field. Soil analyses were conducted on loose soil collected from rhizosphere of sampled plants and on soil cores taken at center of each sampling site. 
also directly reduce the shoot production potential of individual plants.

However, further work is needed to fully assess the impact of BRR on alfalfa production in the region. BRR has been observed to fluctuate considerably across years $(4,20)$, and the BRR incidence and severity observed in 2005 may be either lower or higher than average. Further, the morphology of lesions from which P. sclerotioides was isolated varied widely, and it is unlikely that $P$. sclerotioides was the sole cause of all of the lesions from which it was successfully isolated. Alfalfa root and crown lesions are frequently the product of the interaction of multiple pathogens (15,30). P. sclerotioides was rarely, if ever, the only fungus growing on or from the surface-sterilized tissue segments from which $P$. sclerotioides was isolated on water agar, although identity and pathogenicity of other fungi were not assessed. the two fields sampled extensively. HowFinally, the relationship between BRR severity and spring regrowth was weak in

ever, it is important to note several factors that may have limited our ability to detect an overall significant relationship if it existed. Sampling was conducted very early in the spring, which may have precluded our ability to successfully differentiate winterkill from normal variability in alfalfa emergence from dormancy. Plants remaining in both fields may have been those most tolerant to BRR; both fields had already passed through four winters, and plants highly susceptible to BRR may have been killed in previous years. Finally, as noted earlier, $P$. sclerotioides activity fluctuates annually. If 2005 was not particularly conducive to BRR development, many of the observed lesions may have developed primarily in a previous year, thereby giving plants at least one season to compensate.

The nonaggregated distribution of BRR observed in the extensively sampled Clinton and Wyoming county fields suggests that $P$. sclerotioides was not introduced recently to the fields on equipment with

Table 3. Assessment of spatial distribution of brown root rot (BRR) in Clinton and Wyoming county, NY, fields sampled at 24 and 23 sites on a grid, respectively

\begin{tabular}{|c|c|c|c|}
\hline $\begin{array}{l}\text { Chi-square test } \\
\text { Field }\end{array}$ & $\chi^{2}(\mathrm{df})$ & $P^{\mathbf{a}}$ & Pattern $^{\text {b }}$ \\
\hline $\begin{array}{l}\text { Clinton } \\
\text { Wyoming }\end{array}$ & $\begin{array}{l}98.81(23) \\
61.70(22)\end{array}$ & $\begin{array}{l}<0.0001 \\
<0.0001\end{array}$ & $\begin{array}{l}\text { Not uniform; random or aggregated } \\
\text { Not uniform; random or aggregated }\end{array}$ \\
\hline $\begin{array}{l}\text { Mantel test } \\
\text { Field }\end{array}$ & $r^{\mathrm{c}}$ & $P^{d}$ & Pattern $^{\text {b }}$ \\
\hline $\begin{array}{l}\text { Clinton } \\
\text { Wyoming }\end{array}$ & $\begin{array}{r}0.0486 \\
-0.0655\end{array}$ & $\begin{array}{l}0.5998 \\
0.4436\end{array}$ & $\begin{array}{l}\text { Not aggregated; random or uniform } \\
\text { Not aggregated; random or uniform }\end{array}$ \\
\hline $\begin{array}{l}\text { SADIE } \\
\text { Field } \\
\end{array}$ & $I_{\mathrm{a}}{ }^{\mathrm{e}}$ & $P_{\mathrm{a}}^{\mathrm{f}}$ & Pattern $^{\text {b }}$ \\
\hline $\begin{array}{l}\text { Clinton } \\
\text { Wyoming }\end{array}$ & $\begin{array}{l}1.054 \\
0.900\end{array}$ & $\begin{array}{l}0.3205 \\
0.6282\end{array}$ & $\begin{array}{l}\text { Random; not uniform or aggregated } \\
\text { Random; not uniform or aggregated }\end{array}$ \\
\hline \multicolumn{4}{|c|}{$\begin{array}{l}\text { a } P \text { value from a test of the null hypothesis }\left(H_{0}\right) \text { that BRR frequency is independent of sampling site. } \\
\text { b Spatial pattern of BRR incidence suggested by the corresponding test. As proposed by Perry et al. } \\
\text { (38), BRR frequencies, rounded to the nearest integer, were used in the place of counts for SADIE. } \\
\text { The same approach was extended to the Mantel tests. } \\
\text { c Normalized Mantel statistic (10); values of } r \text { approaching } \pm 1 \text { from unity represent progressively } \\
\text { greater aggregation. } \\
\text { d } P \text { value from a test of } H_{0} \text { that differences in BRR frequency between all possible pairs of sampling } \\
\text { sites are not correlated to Euclidian distances between corresponding pairs of sampling sites. } \\
\text { e Index of aggregation (36); values of } I_{\mathrm{a}}<1,=1 \text {, and }>1 \text { represent uniform, random, and aggregated } \\
\text { spatial patterns. } \\
\text { f } P \text { value from a test of } H_{0} \text { that the minimum distance that individuals would need to be moved from } \\
\text { their corresponding sampling sites to achieve a uniform spatial distribution is not different from the } \\
\text { minimum distance expected under a random assignment of individuals to sites. }\end{array}$} \\
\hline
\end{tabular}

contaminated soil. The distribution of BRR was not aggregated at the field level, and the highest incidence of BRR was not found at the machinery entry points to the fields. The detection of BRR at all sampling locations in many of the fields sampled at four sites further supports the conclusion that $P$. sclerotioides was not introduced recently. The results suggest that $P$. sclerotioides previously escaped detection or that it was introduced by another means. In Wyoming, where BRR was first reported in 1996, $P$. sclerotioides is widespread in nonagricultural soils (39), suggesting that the pathogen has long been present and could be native. Recent Canadian research indicates that $P$. sclerotioides contributes to alfalfa spring blackstem and leaf spot, causing foliar lesions similar to those produced by $P$. medicaginis $(23,49)$. If foliar infection is indeed common, aerial dispersal of conidia of P. sclerotioides may also occur.

The strong relationship between BRR incidence and soil factors suggests that the observed distribution of BRR within the Clinton and Wyoming county fields may have been driven by differences in soil microenvironments. Variation in relative soil saturation was a significant explanator of the nonuniform distribution of BRR in both fields. While soil strength and soil clay content were not consistent explanators across fields, they were significant explanators of BRR either across sampling sites with low stand density or across all sampling sites in individual fields. Whether high levels of the factors promoted or inhibited BRR, however, is not immediately apparent. Because both alfalfa fields had already passed through four winters and incurred considerable stand decline prior to spring 2005, the plants most susceptible to BRR may have already been killed in the field microenvironments particularly conducive to BRR by the time sampling was conducted. Indeed, sites with low alfalfa stand density exhibited lower BRR severity in both fields. The present observational study suggests that it is reasonable to hypothesize that edaphic factors influence BRR, but experimental approaches will be

Table 4. Mean and standard deviation of brown root rot (BRR) incidence and soil characteristics across sampling locations within two fields sampled extensively in spring $2005^{\mathrm{a}}$

\begin{tabular}{|c|c|c|c|c|c|c|}
\hline Field $^{b}$ & $\mathbf{B R R}^{\mathbf{c}}$ & Clay $^{d}$ & POM $^{\mathrm{e}}$ & $\operatorname{Str}^{\mathrm{f}}$ & Saturg & Soil types \\
\hline Wyoming County, NY & $\begin{array}{c}\mathbf{0 . 2 4} \\
(0.13)\end{array}$ & $\begin{array}{l}\mathbf{1 4 . 6 9} \\
(1.37)\end{array}$ & $\begin{array}{c}\mathbf{0 . 6 3} \\
(0.10)\end{array}$ & $\begin{array}{c}\mathbf{1 . 1 3} \\
(0.28)\end{array}$ & $\begin{array}{c}\mathbf{0 . 6 7} \\
(0.06)\end{array}$ & Conesus gravelly silt-loam \\
\hline Clinton County, NY & $\begin{array}{c}\mathbf{0 . 1 6} \\
(0.14)\end{array}$ & $\begin{array}{l}\mathbf{1 2 . 5 1} \\
(4.62)\end{array}$ & $\begin{array}{c}\mathbf{0 . 8 1} \\
(0.32)\end{array}$ & $\begin{array}{c}\mathbf{0 . 7 8} \\
(0.21)\end{array}$ & $\begin{array}{c}\mathbf{0 . 7 1} \\
(0.13)\end{array}$ & $\begin{array}{l}\text { Hoagensburg loam, Mino fine sandy loam, Muskel- } \\
\text { lunge silty clay loam, Nickelville very fine sandy } \\
\text { loam, Swanton loam, and Trout River gravelly loam }\end{array}$ \\
\hline
\end{tabular}

\footnotetext{
a Means are in bold type; standard deviations are in parentheses.

${ }^{\mathrm{b}}$ Sampling was conducted at 23 sites in the Wyoming County field and 24 sites in the Clinton County field.

${ }^{c}$ BRR incidence; approximately 30 plants were analyzed for Phoma sclerotioides at each sampling site.

${ }^{\mathrm{d}}$ Clay content (percent).

e Particulate organic matter content (percent).

${ }^{\mathrm{f}}$ Soil strength (MPa), a measure of soil compaction.

g Soil saturation (proportion of available soil pore space filled with water) of field-moist soil at time of plant sampling.
} 
Table 5. Parameter estimates of cumulative logistic regression models used to evaluate the influence of soil characteristics and stand density on brown root rot (BRR) severity in extensively sampled New York alfalfa production fields ${ }^{\mathrm{a}}$

\begin{tabular}{llccr}
\hline Field & Variable & $\begin{array}{c}\text { Parameter } \\
\text { estimate }^{\mathbf{c}}\end{array}$ & $\begin{array}{c}\text { Standard } \\
\text { error }^{\mathbf{d}}\end{array}$ & P value \\
\hline Wyoming County, NY & Intercept 1 & -6.365 & 1.617 & $<0.0001$ \\
& Intercept 2 & -4.865 & 1.601 & 0.0024 \\
& Intercept 3 & -4.250 & 1.596 & 0.0078 \\
& Clay & 0.0097 & 0.100 & 0.9230 \\
& POM & 0.914 & 1.157 & 0.4299 \\
& Stand 0 & -4.126 & 1.431 & 0.0039 \\
Stinton County, NY & Strength & -2.033 & 0.619 & 0.0010 \\
& Rel satur & 6.338 & 2.610 & 0.0152 \\
& Clay*stand & 0.241 & 0.091 & 0.0078 \\
& Intercept 1 & -5.187 & 1.200 & $<0.0001$ \\
& Intercept 2 & -4.522 & 1.183 & 0.0001 \\
& Intercept 3 & -3.565 & 1.171 & 0.0023 \\
& Intercept 4 & -3.178 & 1.168 & 0.0065 \\
& Clay & -0.068 & 0.036 & 0.0596 \\
& POM & -0.245 & 0.498 & 0.6223 \\
& Stand 0 & -1.921 & 0.724 & 0.0080 \\
& Strength & 0.904 & 0.772 & 0.2415 \\
& Rel satur & 2.355 & 1.337 & 0.0782 \\
& Str*stand & 0.245 & 0.826 & 0.0133 \\
\hline
\end{tabular}

a More than 700 plants, collected at 23 to 24 sites, were assessed in each field.

b Intercept 1, 2, 3, 4 = intercepts for the cumulative log-odds models, listed in order of ascending BRR severity cut-point; clay = percent clay; $\mathrm{POM}=$ percent particulate organic matter; stand $0=$ dummy variable for low (relative to average) stand density; strength = soil strength, a measure of compaction; rel satur = relative soil saturation; clay*stand = interaction between clay and stand density; and str*stand $=$ interaction between soil strength and stand density. BRR severity was rated on a 0 (Phoma sclerotioides not detected) to 5 (P. sclerotioides detected; lesions completely girdle root or crown) scale; because of small sample sizes at the highest severity levels, severity levels 3, 4, and 5 were pooled for the Wyoming County field and levels 4 and 5 were pooled for the Clinton County field in the analysis.

c Wald chi-square, corrected for overdispersion by using the ratio of the Pearson goodness-of-fit chisquare to its degrees of freedom to scale the original Wald chi-square (1).

d Corrected for overdispersion by multiplying the original standard error by the ratio of the Pearson goodness-of-fit chi-square to its degrees of freedom (1).

needed to confirm that relative soil saturation, and possibly soil strength and soil clay content, influence BRR incidence.

Although $P$. sclerotioides has never been previously reported in the eastern United States, the widespread distribution of $P$. sclerotioides in New York, Vermont, and New Hampshire observed in this study is not surprising. Despite a climate conducive to low-temperature fungi, research on lowtemperature pathogens of alfalfa in the northern United States has been lacking (29). Further, the slow rate of growth that $P$. sclerotioides exhibits in culture at room temperature (42), and the low frequency with which $P$. sclerotioides is isolated during the summer months (34), make it unlikely that the pathogen would have been recovered from samples submitted to diagnostic labs or from roots collected in other survey efforts.

The widespread distribution and high incidence of BRR observed in New York, Vermont, and New Hampshire alfalfa production fields coupled with the prevalence of BRR lesions extending into the root and crown cortex suggest that further work is needed to develop management strategies for the disease in the Northeast. Resistance to BRR in alfalfa is heritable (18), and significant differences in BRR resistance have been observed in alfalfa varieties grown in Alberta (4). Identification of the relative BRR susceptibility of alfalfa varieties adapted to the Northeast is needed to assess which commercially available varieties are best suited to fields with a history of severe BRR and to identify sources of resistance for future breeding.

\section{ACKNOWLEDGMENTS}

This research was funded in part by Cornell University Hatch Project NYC 153433. We thank Alexandra $\mathrm{H}$. Baker for her assistance with the laboratory work and Donald R. Viands (Department of Plant Breeding and Genetics, Cornell University) and the two anonymous reviewers for their helpful comments on earlier drafts of the manuscript. We are particularly grateful for the assistance of Carl Albers, Peter Barney, Jennifer Beckman, and Bruce Tillapaugh of Cornell Cooperative Extension; Everett D. Thomas of the W.H. Miner Institute in Chazy, NY; Eric Bever of Champlain Valley Agronomics in Peru, NY; Heather Darby of University of Vermont Extension; and Steven Turaj and Tom Buob of University of New Hampshire Cooperative Extension in the 2005 survey of alfalfa production fields. Special thanks are extended to Brett and Jay Dickson and Everett D. Thomas for generously providing field sites for the pathogenicity testing and to Carl Albers for helping with site selection and plot establishment for pathogenicity testing. We also thank the W.H. Miner Institute, Greg and David Chamberlain, and the other growers who participated in the survey efforts. Finally, we thank F. A. Gray, University of Wyoming, for donating the P. sclerotioides "Berg" isolate and seed of "Multi-plier" alfalfa.

\section{LITERATURE CITED}

1. Allison, P. D. 2001. Logistic Regression Using the SAS System: Theory and Application. SAS
Publishing, BBU Press, Cary, NC.

2. Anonymous. Comparative Climatic Data for the U.S., Normal Precipitation 1961-1990. Northeast Regional Climate Center, Cornell University, Ithaca, NY. Online publication.

3. Berkenkamp, B., and Baenziger, H. 1969. The reaction of sweetclover varieties to brown root rot. Can. J. Plant Sci. 49:181-189.

4. Berkenkamp, B., Bittman, S., and McCartney, D. 1991. Resistance of alfalfa cultivars to brown root rot. Can. J. Plant Sci. 71:211-213.

5. Boerema, G. H., de Gruyter, J., and van Kesteren, H. A. 1994. Contributions toward a monograph of Phoma (Coelomycetes) - III 1. Section Plenodomus: Taxa often with a Leptosphaeria teleomorph. Persoonia 15(4):431487.

6. Cambardella, C. A., Gajda, A. M., Doran, J. W., Wienhold, B. J., and Kettler, T. A. 2001 Estimation of particulate and total organic matter by weight loss-on-ignition. Pages 349-359 in: Assessment Methods for Soil Carbon. R Lal, J. M. Kimble, R. F. Follett, and B. A Stewart, eds. Lewis Publishers, CRC Press, Boca Raton, FL.

7. Cormack, M. W. 1934. On the invasion of roots of Medicago and Melilotus by Sclerotinia sp. and Plenodomus meliloti D. and S. Can. J. Res. 11:474-480.

8. Dale, M. R. T., Dixon, P., Fortin, M.-J., Legendre, P., Myers, D. E., and Rosenberg, M. S. 2002. Conceptual and mathematical relationships among methods for spatial analysis. Ecography 25:558-577.

9. Davidson, J. G. N. 1990. Brown root rot. Pages 29-31 in: Compendium of Alfalfa Diseases. D. L. Stuteville and D. C. Erwin, eds. American Phytopathological Society, St. Paul MN.

10. Fortin, M.-J., and Gurevitch, J. 2001. Mantel tests: Spatial structure in field experiments. Pages 308-326 in: Design and Analysis of Ecological Experiments, 2nd ed. S. M. Scheiner and J. Gurevitch, eds. Oxford University Press, Oxford.

11. Gaudet, D. A., and Bhalla, M. K. 1988. Survey for snow mold diseases of winter cereals in central and northern Alberta, 1983-87. Can. Plant Dis. Surv. 68(1):15-19.

12. Gee, G. W., and Bauder, J. W. 1986. Particlesize analysis. Pages 383-411 in: Methods of Soil Analysis, Part 1. Agron. Monogr. 9. A Klute, ed. Am. Soc. Agron./Soil Sci. Soc. Am., Madison, WI.

13. Gill, J. S., Hunt, S., Sivasithamparam, K., and Smettem, K. R. J. 2004. Root growth altered by compaction of a sandy loam soil affects severity of Rhizoctonia root rot of wheat seedlings. Aust. J. Exp. Agric. 44:595-599.

14. Gill, J. S., Sivasithamparam, K., and Smettem, K. R. J. 2000. Soil types with different texture affects development of Rhizocotonia root rot of wheat seedlings. Plant Soil 221:113-120.

15. Grau, C. R. 1996. Disease complexes. Pages 453-472 in: Pasture and Forage Crop Pathology. S. Chakraborty, K. T. Leath, R. A. Skipp, G. A Pederson, R. A. Bray, G. C. M. Latch, and F. W. Nutter, eds. Am. Soc. Agron./Crop Sci. Soc. Am./Soil Sci. Soc. Am., Madison, WI.

16. Harveson, R. M., Smith, J. A., and Stroup, W. W. 2005. Improving root health and yield of dry beans in the Nebraska Panhandle with a new technique for reducing soil compaction. Plant Dis. 89:279-284.

17. Hollingsworth, C. R., and Gray, F. A. 1999. First report of brown root rot on alfalfa caused by Phoma sclerotioides in the continental United States. Plant Dis. 83:1071.

18. Hollingsworth, C. R., Gray, F. A., and Groose, R. W. 2005. Evidence for the heritability of resistance to brown root rot of alfalfa, caused by Phoma sclerotioides. Can. J. Plant Pathol. 27:64-70.

19. Hollingsworth, C. R., Gray, F. A., Groose, R. W., and Mims, C. W. 2002. Morphological re- 
sponses of Canadian and U.S.A. isolates of Phoma sclerotioides to different growth media, temperatures and light. Mycotaxon 131:331339.

20. Hollingsworth, C. R., Gray, F. A., Koch, D. W., Groose, R. W., and Heald, T. E. 2003. Distribution of Phoma sclerotioides and incidence of brown root rot of alfalfa in Wyoming, U.S.A. Can. J. Plant Pathol. 25:215-217.

21. Hosmer, D. W., and Lemeshow, S. 2000. Applied Logistic Regression. John Wiley \& Sons, New York.

22. Hwang, S. F., and Flores, G. 1987. Effects of Cylindrocladium gracile, Fusarium roseum and Plenodomus meliloti on crown and root rot, forage yield, and winterkill of alfalfa in north-eastern Alberta. Can. Plant Dis. Surv. 67(2):31-33.

23. Hwang, S. F., Wang, H., Gossen, B. D., Chang, K. F., Turnbull, G. D., and Howard, R. J. 2006. Impact of foliar diseases on photosynthesis, protein content and seed yield of alfalfa and efficacy of fungicide application. Eur. J. Plant Pathol. 115:389-399.

24. Kettler, T. A., Doran, J. W., and Gilbert, T. L. 2001. Simplified method for particle-size determination. Soil Sci. Soc. Am. J. 65:849-852.

25. Klute, A. 1986. Water retention: Laboratory methods. Pages 635-662 in: Methods of Soil Analysis, Part 1. Agron. Monogr. 9. A. Klute, ed. Am. Soc. Agron./Soil Sci. Soc. Am., Madison, WI.

26. Larsen, J. E., Hollingsworth, C. R., Flor, J., Dornbusch, M. R., Simpson, N. L., and Samac, D. A. 2007 Distribution of Phoma sclerotioides on alfalfa and winter wheat crops in the North Central United States. Plant Dis. 91:551-558.

27. Larsen, R. C., Grau, C. R., Vandemark, G. J., Hughes, T. J., and Hudelson, B. D. 2004. First report of brown root rot of alfalfa caused by Phoma sclerotioides in Wisconsin. Plant Dis. 88:769.

28. Larsen, R. C., Hollingsworth, C. R., Vandemark, G. J., Gritsenko, M. A., and Gray, F. A. 2002. A rapid method using PCR-based SCAR markers for detection and identification of Phoma sclerotioides: The cause of brown root rot disease of alfalfa. Plant Dis. 86:928-932.

29. Leath, K. T. 1989. Diseases and stand persis- tence in the United States. Pages 465-479 in: Persistence of Forage Legumes. G. C. Marten, A. G. Matches, R. F. Barnes, R. W. Brougham, R. J. Clements, and G. W. Sheath, eds. Soc. Agron./Crop Sci. Soc. Am./Soil Sci. Soc. Am., Madison, WI

30. Leath, K. T., Edwin, D. C., and Griffin, G. D. 1988. Diseases and nematodes. Pages 621-670 in: Alfalfa and Alfalfa Improvement. A. A. Hansen, D. K. Barnes, and R. R. Hill, eds. Soc. Agron./Crop Sci. Soc. Am./Soil Sci. Soc. Am. Madison, WI.

31. Lebeau, J. B., and Logsdon, C. E. 1958. Snow mold of forage crops in Alaska and Yukon. Phytopathology 48:148-150.

32. Legendre, P., and Fortin, M.-J. 1989. Spatial pattern and ecological analysis. Vegetatio. 80:107-138.

33. Madden, L. V. 1989. Dynamic nature of within-field disease and pathogen distributions. Pages 96-126 in: Spatial Components of Plant Disease Epidemics. M. J. Jeger, ed. Prentice Hall, Englewood Cliffs, NJ.

34. McDonald, W. C. 1955. The distribution and pathogenicity of the fungi associated with crown and root rotting of alfalfa in Manitoba. Can. J. Agric. Sci. 35:309-321.

35. Mikkelson, M. 1997. Summary of plant diseases diagnosed on commercial and yard and garden plants in 1996. Montana State University, Plant Disease Clinic, Bozeman.

36. Perry, J. N. 1998. Measures of spatial pattern for counts. Ecology 79(3):1008-1017.

37. Perry, J. N., Liebhold, A. M., Rosenberg, M. S., Dungan, J., Miriti, M., Jakomulska, A., and Citron-Pousty, S. 2002. Illustrations and guidelines for selecting statistical methods for quantifying spatial pattern in ecological data. Ecography 25:578-600.

38. Perry, J. N., Winder, L., Holland, J. M., and Alston, R. D. 1999. Red-blue plots for detecting clusters in count data. Ecol. Lett. 2:106113.

39. Reedy, C. J., Gray, F. A., Larsen, R. C., Groose, R. W., and Gill, J. R. 2006. Occurrence of brown root rot of alfalfa and its causal organism, Phoma sclerotioides, in agricultural and nonagricultural sites in the Big Horn Basin ecosystem of Wyoming, United States. Can. J. Plant Pathol. 28(2):363.
40. Salonen, A. 1962. Plenodomus meliloti Dearness \& Sanford found in Finnish Lappland. J. Sci. Agric. Soc. Finland 34(4):169-172.

41. Samac, D. A., and Hollingsworth, C. R. 2004. Identification of Phoma sclerotioides, the causal agent of brown root rot, in Wisconsin and Minnesota. Proc. 39th N. Am. Alfalfa Improv. Conf. 18th Trifolium Conf. 18-21 July 2004. Quebec City, Quebec. http://www.naaic. org/Meetings/National/2004NAAIC\&TC/session -2.htm

42. Sanford, G. B. 1933. A root rot of sweet clover and related crops caused by Plenodomus meliloti Dearness and Sanford. Can. J. Res. Sect. C. 8:337-347.

43. Schmale, D. G., III, Shah, D. A., and Bergstrom, G. C. 2005. Spatial patterns of viable spore deposition of Gibberella zeae in wheat fields. Phytopathology 95:472-479.

44. Scott, S. C., Goldberg, M. S., and May, N. E. 1997. Statistical assessment of ordinal outcomes in comparative studies. J. Clin. Epidemiol. 50(1):45-55.

45. Singh, U. P., and Singh, R. B. 1983. The effect of soil texture, soil mixture, soil moisture and depth of soil on carpogenic germination of Sclerotinia sclerotiorum. J. Plant Dis. Prot. 90(6):662-669.

46. Stokes, M. E., Davis, C. S., and Koch, G. G. 2000. Categorical Data Analysis Using the SAS System, 2nd ed. SAS Institute, Cary, NC.

47. Topp, G. C., Galganov, Y. T., Ball, B. C., and Carter, M. R. 1993. Soil water desorption curves. Pages 569-579 in: Soil Sampling and Methods of Analysis. M. R. Carter, ed. Can Soc. Soil Sci. Lewis Publishers, Boca Raton FL.

48. Tsukamoto, J. Y. 1965. Phenotypic characteristics of alfalfa tolerant to brown root rot. Can. J. Plant Sci. 45:197-198.

49. Wang, H., Hwang, S. F., Chang, K. F., Gossen, B. D., Turnbull, G. D., and Howard, R. J. 2004. Assessing resistance to spring black stem and leaf spot of alfalfa caused by Phoma spp. Can. J. Plant Sci. 84:311-317.

50. Wunsch, M. J., Baker, A. H., Larsen, R. C. and Bergstrom, G. C. 2006. Distribution and prevalence of brown root rot of forage legumes in the northeastern United States. (Abstr.) Phytopathology 96:S125. 